\title{
Disseminated Intravascular Coagulation: A Single
}

\section{Center Experience}

\author{
Omer Ekinci, Omer Candar, Ali Dogan, Ramazan Esen, Cengiz Demir \\ Van Yuгuncu Yil University Faculty of Medicine Department of Hematology, Van, Turkey
}

\begin{abstract}
We aimed to evaluate the clinical and demographic data of adult patients diagnosed with acute disseminated intravascular coagulation (DIC) who had been referred to the hematology unit by other clinics, as well as to evaluate the effect of clinical and laboratory parameters on patient survival.

Materials and Methods: The records of 87 adult patients admitted to the Department of Hematology of Yuzuncu Yil University Faculty of Medicine between January 2013 and May 2017 and diagnosed with acute DIC were retrospectively examined.

Of the patients participating in the study, $64(73.6 \%)$ were female and $23(26.4 \%)$ were male. Regarding the distribution of etiology in patients with acute DIC, the most common etiology, at $49.3 \%$, was obstectic pathologies. Acute DIC was more frequent in women and younger adults $(\mathrm{p}=0.001)$. Patients with trauma had the highest mortality rate $(\mathrm{p}=0.001)$. Patients diagnosed with acute DIC who died as a result were older, and mortality was higher in males $(\mathrm{p}<0.001$ for both). Comparing ISTH scores, patients with acute DIC had significantly higher mortality ( $p=0.028$ ).

In this study, a majority of the patients diagnosed with acute DIC were young and female. Despite their high incidence of acute DIC however, the mortality rate for young female patients was low. The mortality rate was higher in elderly and male patients, although intensive treatment was administered following diagnosis of acute DIC. We believe that early diagnosis and appropriate treatment are of critical importance for patients thought to have acute DIC, regardless of underlying condition.
\end{abstract}

Key Words: Disseminated intravascular coagulation, acute, survival

\section{Introduction}

Disseminated intravascular coagulation (DIC) is a systemic disorder presenting with thrombosis and hemorrhage. DIC causes widespread formation of fibrin clots in blood vessels and, consequently, disruption of blood flow to organs, resulting in multiple organ failure. Continual clotting may lead to severe bleeding due to consumption of thrombocytes and clotting factors (1). DIC does not appear alone, but always develops secondary to an underlying disease. The most common causes of DIC are infections and related sepsis. Viral and parasitic infections may result in DIC, as well as both gram-positive and negative bacteria (2). Severe trauma and burns can also cause acute DIC. Fifteen percent of solid or hematologic (myeloproliferative and lymphoproliferative tumors) malignancies may be complicated by DIC. More than $50 \%$ of patients with obstetric complications (amniotic fluid embolism, abrubtio placenta, placenta previa, etc.) have DIC. It may also occur in some vascular disorders (large aneurysms, Kasabach Merritt syndrome, etc.), severe organ damage (severe pancreatitis, hepatic insufficiency, etc.), and toxic (snake bite) or immunological reactions (hemolytic transfusion reactions, transplant rejection, etc.) (3). Clinical presentation of DIC may vary. Some patients are completely asymptomatic while in others with laboratory findings of DIC there is no bleeding or thrombosis. In some patients, severe symptoms such as bleeding, thrombosis, or purpura fulminans may occur (4). There is no test that can by itself diagnose intravascular coagulation; both clinical and laboratory findings are important for diagnosis. For this reason, a number of scoring systems have been created to diagnose DIC. Among them, the scoring system developed by the International Society of Thrombosis and Haemostasis (ISTH) has gained prominence (5). The ISTH scoring system is shown in Table 1. (6). It should be emphasized that the most important step in the treatment of DIC is treatment of the underlying disease. Thrombocyte and coagulation factors may also be administered as supportive treatment. Heparin treatment has been reported to 
be of great value in some cases of acute DIC, especially those presenting with thrombosis (7).

Table 1. ISTH scoring system for the diagnosis of disseminated intravascular coagulation

\begin{tabular}{|c|c|}
\hline Parameter & Score \\
\hline $\begin{array}{c}\text { Presence of } \\
\text { underlying disease } \\
\text { known to cause } \\
\text { DIC }\end{array}$ & $\begin{array}{l}\text { No }=0 \\
\text { Yes }=2\end{array}$ \\
\hline $\begin{array}{l}\text { Platelet count } \\
\left(\text { cells } / \mathrm{mm}^{3}\right)\end{array}$ & $\begin{array}{l}>100,000=0 \\
<100,000=1 \\
<50,000=2\end{array}$ \\
\hline $\begin{array}{c}\text { Increase in D- } \\
\text { dimer and/or fibrin } \\
\text { degradation } \\
\text { products (FDP) }\end{array}$ & $\begin{array}{c}\text { No increase }=0 \\
\text { Moderate increase }=2 \\
\text { Strong increase }=3\end{array}$ \\
\hline $\begin{array}{l}\text { Prothrombin time } \\
\text { (PT) test }\end{array}$ & $\begin{array}{l}<3 \text { seconds }=0 \\
\quad 3-6 \text { seconds }=1 \\
>6 \text { second } s=2\end{array}$ \\
\hline $\begin{array}{c}\text { Fibrinogen level } \\
(\mathrm{gr} / \mathrm{L})\end{array}$ & $\begin{array}{l}>1 \mathrm{gr} / \mathrm{L}=0 \\
<1 \mathrm{gr} / \mathrm{L}=1\end{array}$ \\
\hline
\end{tabular}

Scoring: A score of 5 or greater indicates a definitive diagnosis of DIC.

A score of less than 5 indicates that DIC has not yet developed although it may in future. The test should be repeated on a daily basis.

\section{Materials and Methods}

For the present study, the data of 2,416 patients hospitalized at Van Yuzuncu Yil University Faculty of Medicine Hospital between January 2013 and May 2017 and referred to the Hematology Department were retrospectively examined. ISTH scores based on clinical and laboratory findings were used to diagnose DIC. Patients with a score of 5 or more were considered to have acute DIC. In total, 87 patients with a diagnosis of acute DIC were included in the study. The etiological, clinical, and laboratory characteristics of the patients were examined and survival status was evaluated.

\section{Statistical Analysis:}

Descriptive statistics for continuous variables were expressed as mean and standard deviation, while categorical variables were expressed as numbers and percentages. Independent t test was performed to compare group averages for continuous variables. A $p$ value of $<0.05$ was considered statistically significant. The statistical package program SPSS (version 20.0) was used for the calculations.
Ethical approval for this study was obtained from the ethics committee of Van Yuzuncu Yil University Faculty of Medicine.

\section{Results}

Of the patients, $64(73.6 \%)$ were female and 23 $(26.4 \%)$ were male. The mean age of the patients was $35 \pm 11.2$ years. Obstetric pathologies $(49.3 \%)$ [postpartum atony $(27.9 \%)$, stillbirth $(23.3 \%)$, placental abruption (25.6\%), preeclampsia $(11.7 \%)$, eclampsia $(6.9 \%)$, and placenta previa $(4.6 \%)]$ were the most common etiologic agents in patients with acute DIC. Following obstectric pathologies were sepsis $(26.3 \%)$, trauma $(9.1 \%)$, solid malignancies $(6.8 \%)$, hematologic malignancies $(5.7 \%)$, snake bites $(1.4 \%)$, and alpha-lipoic acid poisoning (1.4\%). Demographic and etiological characteristics of the patients are presented in Table 2. Examining the association of DIC with age and gender, acute DIC was more prevalent in women and younger adults to a statistically significant extent $(p=0.001)$. Regarding patient age with respect to survival, patients who died were of significantly more advanced age $(p=0.001)$. Concerning gender and survival, although DIC was less common in male patients, the mortality rate was significantly higher for males $(69.6 \% ; p=0.003)$. When whole blood counts were compared with regard to survival, platelet counts were found to be significantly lower in patients who died $(p=0.005)$. Viewed in terms of survival, D-dimer levels were significantly higher in patients who survived $(p=0$ .016). There was no statistically significant difference in biochemical parameters (ALT, AST, and creatinine) with regard to patient survival $(\phi>$ 0.05 for all three). The ISTH scores of patients who died were significantly higher than those of patients who survived ( $p=0.028$ ) (Table 3 ). When the relationship between disease etiology and survival was examined, although obstetric pathologies were the single most common cause, the mortality rate for trauma cases was $75 \%$, a statistically significant result $(p=0.001)$.

\section{Discussion}

Numerous studies worldwide have demonstrated that sepsis is the most common cause in the etiology of DIC. Di Nisio et al., investigating the underlying causes of patients with DIC, found that sepsis (88\%) was the most common cause, followed by hematological cancers $(29 \%)$, obstetric complications $(18 \%)$, solid cancers $(11 \%)$, trauma $(11 \%)$, liver 
Table 2. Demographic and etiological characteristics of patients diagnosed with acute DIC

\begin{tabular}{ll|c|c}
\hline & & Number (n) & Percentage (\%) \\
\hline \multirow{3}{*}{ Gender } & Female & 64 & 73.6 \\
& Male & 23 & 26.4 \\
& Total & 87 & 100.0 \\
& Obstetric pathologies & 43 & 49.3 \\
& Sepsis & 23 & 26.3 \\
& Trauma & 8 & 9.1 \\
& Solid malignancies & 6 & 6.8 \\
& Hematologic malignancies & 5 & 5.7 \\
& Snake bite & 1 & 1.4 \\
& Alpha-lipoic acid poisoning & 1 & 1.4 \\
& Total & 87 & 100.0 \\
& Deaths & 31 & 35.6 \\
& Survivival & 56 & 64.4 \\
& Total & 87 & 100.0 \\
\hline
\end{tabular}

Table 3. Evaluation of mortality of patients diagnosed with acute DIC

\begin{tabular}{lccc}
\hline & $\begin{array}{c}\text { Deaths }(\mathrm{n}=31) \\
\text { Mean } \pm \text { Std. Dev. }\end{array}$ & $\begin{array}{c}\text { Survivors }(\mathrm{n}=56) \\
\text { Mean } \pm \text { Std. Dev. }\end{array}$ & $p$ value \\
\hline Age (years) & $47.4 \pm 16.8$ & $32.4 \pm 10.6$ & 0.001 \\
Female/Male & $16 / 15$ & $49 / 7$ & 0.003 \\
ISTH score & $6.8 \pm 0.8$ & $5.9 \pm 1.2$ & 0.028 \\
WBC (/L) & $10.4 \times 10^{9} \pm 7.8 \times 10^{9}$ & $11.8 \times 10^{9} \pm 6.6 \times 10^{9}$ & 0.186 \\
Hb (g/dL) & $8.2 \pm 2.7$ & $8.4 \pm 2.4$ & 0.874 \\
Plt $(/ \mathrm{L})$ & $36.4 \times 10^{9} \pm 23.6 \times 10^{9}$ & $68.4 \times 10^{9} \pm 34.8 \times 10^{9}$ & 0.005 \\
MPV (fL) & $9.4 \pm 2.6$ & $9.2 \pm 2.4$ & 0.372 \\
MCV (fL) & $88.2 \pm 9.8$ & $86.3 \pm 4.8$ & 0.062 \\
Lymphocytes $(/ \mathrm{mL})$ & $2184.7 \pm 1962.4$ & $2366.8 \pm 546.2$ & 0.578 \\
Neutrophils $/(\mathrm{mL})$ & $8714.4 \pm 6618.3$ & $9812.7 \pm 6312$ & 0.081 \\
D-Dimer $(\mathrm{ng} / \mathrm{mL})$ & $20.6 \pm 14.2$ & $34.3 \pm 18.8$ & 0.016 \\
Fibrinogen $(\mathrm{mg} / \mathrm{dL})$ & $168.4 \pm 118.6$ & $144.8 \pm 119.2$ & 0.475 \\
Creatinine $(\mathrm{mg} / \mathrm{dL})$ & $1.9 \pm 1.4$ & $1.6 \pm 1.1$ & 0.074 \\
INR (International & $3.3 \pm 2.8$ & $2.2 \pm 1.6$ & 0.084 \\
Normalized Ratio) & & &
\end{tabular}

diseases (8\%), operations (7\%), vascular malformations (4\%), and severe toxic or immunological reactions (3\%) (8). The most common etiology for patients with DIC in the present study was obstetric pathologies (49.3\%), followed by sepsis $(26.3 \%)$. One of the most common underlying causes of disseminated intravascular coagulation is obstetric pathologies. In a study conducted by Naz et al. with 4334 patients at the Obstetrics and Gynecology Department of Ayub Medical College, 40 patients were diagnosed with DIC. Examining the etiology of the patients, they found that 28 patients $(70 \%)$ had eclampsia, $7(17.5 \%)$ had placental abruption, 3
$(7.5 \%)$ had sepsis, $1(2.5 \%)$ had pancytopenia, and 1 $(2.5 \%)$ had placenta previa. The mean age of their patients was 34 years, and 10 cases $(25 \%)$ resulted in maternal death (9). In the present study, the number of patients diagnosed with DIC who had obstetric complications was 43. Of these patients, $12(27.9 \%)$ had postpartum atony, $10(23.3 \%)$ cases resulted in stillbirth, $11(25.6 \%)$ were diagnosed with placental abruption, $5(11.7 \%)$ with pre-eclampsia, $3(6.9 \%)$ with eclampsia, and $2(4.6 \%)$ with placenta previa. The mean age of the patients with obstetric complications in our study was 29 years. Two of the 
patients died, one of postpartum atony and the other of pre-eclampsia.

In one study, Klenner et al. found that two elderly patients with no known disease and symptoms of bleeding had low platelet and fibrinogen levels and high PT (prothrombin time) and D-dimer levels. DIC in these patients was associated with adenocarcinoma of unknown primary origin that had metastasized to the bone marrow (10). In the present study, platelet and fibrinogen levels were low and prothrombin time (PT) and D-dimer levels were high in all 6 patients with adenocarcinoma who had been diagnosed with DIC.

Chi et al. studied coagulation factors in 161 of 236 newly diagnosed non-Hodgkin's lymphoma (NHL) patients between July 2008 and December 2014 at the Japanese Ministry of Health and identified 18 patients with DIC (11). In the current study, DIC developed in 5 patients (non-Hodgkin's and Hodgkin's Lymphoma) who had been diagnosed with hematologic malignancies. We believe that the reason for the low number of patients with hematologic malignancies diagnosed with DIC in our study is due to the fact that patients in the hematology department were not included in our study.

Consumption coagulopathy usually develops in head trauma patients. The tissue factor secreted by damaged brain tissue appears to induce DIC. In a study conducted by Aiyagari et al., 3 patients were diagnosed with DIC following severe head trauma resulting from firearm injuries. The patients received transfusions of fresh frozen plasma, apheresis platelets, cryoprecipitate, and Factor VIIa. However, all 3 patients lost their lives despite the improvement in coagulopathy symptoms (12). In the present study, 3 of the 8 patients with trauma developed DIC as a result of firearm injuries. Although all 3 patients received blood and blood products transfusions, none of them survived.

Disseminated intravascular coagulation may also be caused by drug poisoning. In the current study, after a 24-year-old female patient consumed a high dose of alpha-lipoic acid in a suicide attempt, brain hemorrhage occurred and the patient developed DIC. Following supportive care, and transfusion with blood and blood products, the DIC improved.

Demir et al. diagnosed 2 patients with DIC following snake bites. Together with black necrotic tissue in the area around the bite, massive induration, edema, and hematoma developed throughout the affected extremity. After receiving supportive care and transfusion with blood and blood products, the patients recovered and were discharged (13). In the present study, a 47 year-old patient was diagnosed with DIC due to a snake bite. Although the patient's hemoglobin and fibrinogen levels were normal, platelet counts were low. The patient's PT, aPTT (activated partial thromboplastin time), and D-dimer levels were high. Following treatment with fresh frozen plasma, thrombocyte suspension, and supportive care, the patient completely recovered.

In conclusion, the majority of acute DIC patients diagnosed with acute DIC in this retrospective study were young and female. Despite the frequency of a diagnosis of acute DIC in both young and female patients, their mortality rate was low. We believe that the reason for this is that their underlying disease was more likely to be a treatable condition, such as obstetric pathologies. Mortality rates were higher in elderly and male patients with acute DIC in this study, despite the fact that they received intensive treatment. In our estimation this is due to the fact that these patients tended to have diseases with higher mortality rates, such as severe trauma and sepsis. Early diagnosis and appropriate treatment are of vital importance for patients diagnosed with acute DIC, regardless of the underlying condition.

\section{References}

1. Crey, MJ, Rodgers GM. Dissaminated intravascular coagulation; clinical and laboratory aspects. Am J Hematol 19; 5: 65-73.

2. Matsuda T. Clinical aspects of DICDisseminated intravascular coagulation. Pol J Pharmacol 1996; 48: 73-75.

3. Levi M, Toh $\mathrm{CH}$, Thachil J, Watson HG. Guidelines for the diagnosis and management of disseminated intravascular coagulation. British Committee for standart Standarts in Haematology. Br J Haematol 2009; 145: 24-33.

4. Levi M, Ten Ctae H. Disseminated intravascular coagulation. N Engl J Med 1999; 341: 586-592.

5. Taylor FBJ, Toh CH, Hoots WK et al. Towards definition, clinical and laboratory criteria, and a scoring system for disseminated intravascular coagulation. Thromb Haemost 2001; 86: 1327-1330.

6. Gezer S. Dissemine intravasküler koagülasyonun tanı ve tedavisi (Diagnosis and treatment of disseminated intravascular coagulation). Türk hematoloji derneği, Hematolog dergisi (Turkish Hematology Association, Journal of Hematology) 2012: $97-$ 111. 
7. De Jonge E, Levi M, Stoutenbeck CP, Van Deventer SJH. Current drug treatment strategies for disseminated intavascular coagulation. Drugs 1998; 55: 767-777.

8. Di Nisio M, Thachil J, Squizzato A. Management of disseminated intravascular coagulation: A survey of the International Society on Thrombosis and Haemostasis. Thromb Res 2015; 136: 239-242.

9. Naz H, Fawad A, Islam A, Shahid H, Abbasi AU. Disseminated intravascular coagulation. J Ayub Med Coll Abbottabad 2011; 23: 111-113.

10. Klenner AF, Greinacher A, Kuvikova A, Dölken G, Busemann C. Severe disseminated coagulopathy caused by adenocarcinoma with bone marrow metastasis. Onkologie 2013; 36: 292-294.
11. Chi S, Ikezoe T. Disseminated intravascular coagulation in non-Hodgkin lymphoma. Int J Hematol 2015; 102(4): 413-419.

12. Aiyagari V, Menendez JA, Diringer MN. Treatment of severe coagulopathy after gunshot injury to the head using recombinant activated factor VII. J Crit Care 2005; 20: 176-179.

13. Demir C, Atik B, Dilek İ. Yılan Isırığ1 Sonucu Gelişen Yaygın Damar İçi Pıhtılaşması ve Multi Organ Yetmezliği (Widespread intravascular coagulation and multi-organ failure resulting from snake bite). Van Tip Dergisi (Van Journal of Medicine) 2005; 12: 22-25. 